\title{
7 STUDY OF RELIABILITY OF TECHNICAL SYSTEMS RELIABLLITY
}

I. Nazarenko, M. Delembovskyi, O. Dedov, A. Onyshchenko, I. Rogovskii, M. Nazarenko, I. Zalisko

ABSTRACT

The main states of reliability of a technical system and its elements are investigated by the example of vibration platforms for compacting concrete mixtures. Experimental studies on the development of vibration platforms for failure have been carried out. Complex indicators were used, which were the coefficient of technical utilization, the coefficient of availability and durability. The received data of malfunctions was made by fixing by groups of prefabricated units, parts and elements to determine the data on their operating time. Based on these data, the analysis of the operating time of the main elements to failure and the most frequently out of order was carried out. The conducted research identified the main prefabricated units and failing parts: engine, gearbox, synchronizer, vibration exciter, propeller shafts, couplings. At the same time, propeller shafts and couplings most often failed. In some cases, the destruction of bearings in vibration exciters has been evidenced. The parameters of the Weibull distribution law have been determined and graphs have been constructed for the model of reliability and failures of propeller shafts of vibration platforms. A graph of the dependence of reliability on the operating time and graphs of the regularities of the distribution of resource indicators and the distribution function, which served as information for the development of recommendations, were built.

\section{KEYWORDS}

Technical system, reliability, vibration platform, prefabricated units, complex indicators, distribution laws, technical utilization factors, availability and durability.

\subsection{STATEMENT OF THE PROBLEM AND ANALYSIS OF METHODS FOR DETERMINING THE RELIABILITY INDICATORS OF VIBRATION PLATFORMS}

Ensuring the reliability of vibration platforms in the construction industry [1-3] is an important problem of increasing their efficiency. The process of operating technical systems is impossible without performing technical services, the most important task is to restore the working condition of machines or units by eliminating failures during operation, as well as overhaul or refurbishment at manufacturing enterprises. Repair planning assumes the availability of information on reliability indicators in order to perform high-quality repairs with the least amount of time. 
In vibration platforms, when performing work, there is a probability of failure (random and fluctuations) in the process of deviation of specified fluctuations, considered as a result of changes in time of the parameters of the system Camplitude of fluctuations, accelerations, permissible stresses in the structural elements of vibration platforms). The analysis of random events of oscillatory processes [1, 2] makes it possible to assess such deviations associated with the processes of accumulation of failures, which are the subject of the theory of reliability.

Assessment of the reliability of technical systems generally implies an integrated approach to solving the procedure for assessing reliability indicators at all stages of the existence of such systems. Methods for assessing such indicators are based on the use of mathematical models of the existence of a system, depending on the stage of the life cycle of a technical object. The physical essence of the existence of a system is due to the presence of a number of factors and factors that must be taken into account when creating a model.

So at the design stage, methods are used to predict reliability characteristics based on general methods of probability theory, analytical mechanics, theory of machines and devices, resistance of materials, vibration theory, etc.

Structural methods of calculation are characteristic at the stages of manufacturing and operation of technical structures, since they involve the consideration of the system by means of a structural-functional diagram. In such a logical scheme, the transition of a system from one state to another, the relationship between such states, the interaction of system elements, taking into account their functional purpose, manufacturing technologies, and conditions of use are investigated.

Physical methods are used to determine reliability, durability and safety of technical objects for which degradation mechanisms are known under the influence of external and internal factors, which leads to failures - the limiting state during operation. Such methods are based on the representation of processes using mathematical models capable of determining reliability indicators taking into account the design features, manufacturing technology of its individual elements, operating modes, etc.

Each of the methods has its own advantages and disadvantages, therefore, in specific cases, it is more efficient to use a combination of such methods to solve the problem. This approach allows one to obtain a result that has not only an imaginary understanding of the existence of a technical system, but also has a physical essence, confirmed by experimental research.

One of the methods that satisfy an integrated approach to solving the problem is the probabilistic-physical method of reliability analysis. This method of reliability analysis involves the use of probabilistic-physical reliability models, the parameters of which have a specific physical interpretation and relate the value of the probability of failure and the physical (determining) parameter, which leads to failure. Among the advantages of this method, there is a quantitative assessment of the reliability indicators of systems (elements) both on the basis of statistical information about failures and statistical information about physical processes leading to failures. In this case, all data is used in aggregate and separately.

Thus, the application of the above method will make it possible to assess the necessary reliability indicators, including the complete characteristic - the distribution law based on the processing of statistical data on the failure of technical structures. 
Prediction of the reliability of vibration platforms occurs at all stages of design, operation and repair [3-5]. At the same time, it is important to obtain the design parameters of parts and assemblies depending on predicting reliability indicators: mean time between failures, reliability, durability and maintainability.

Today in this area the works of such scientists as: I. Kravchenko, V. Bolotin, A. Barash, A. Pronikov, K. Frolov and others are known. As a basis for research for assessing the reliability of vibration platforms, a model was adopted in which the object under study is in one of the following states: serviceable, faulty, efficient, disabled and extreme. The structural and logical diagram of the technical system and the path of transition from one state to another is shown in Fig. 7.1.

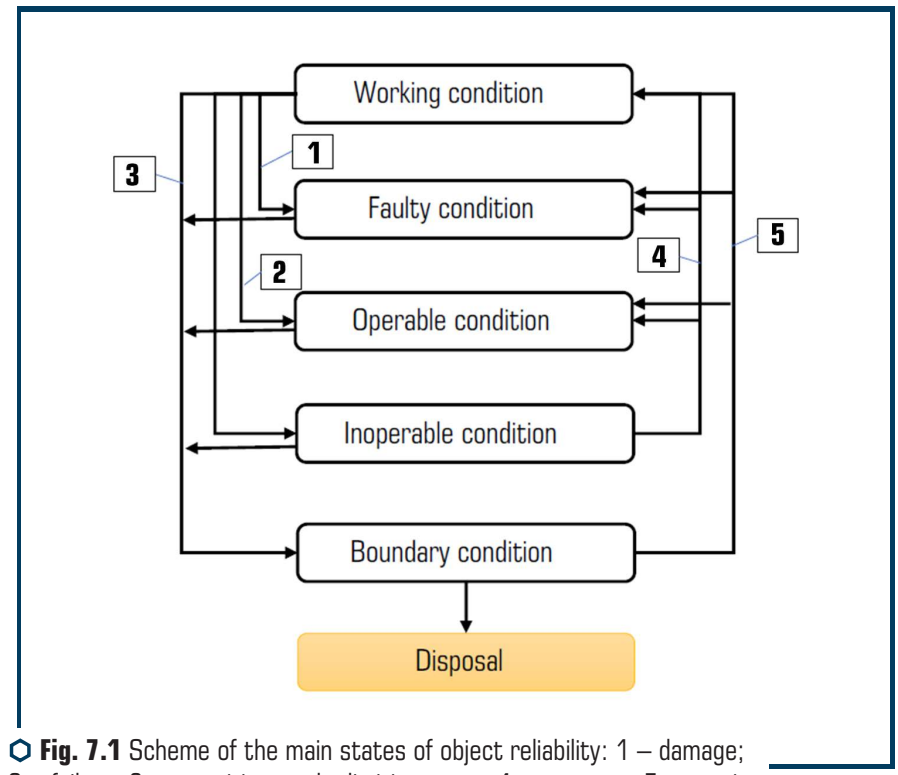

2 - failure; 3 - transition to the limiting state; 4 - recovery; 5 - repair

For the implementation of research, the following states of the system and their evaluation criteria were adopted:

- working condition - a property of the vibration platform, in which it meets all the requirements of the normative, technical and design documentation;

- faulty condition - a property of a vibration platform, in which it does not meet at least one requirement of regulatory, technical and design documentation;

- operable condition - a property of a vibration platform, at which the value of all parameters, characterizing the properties of performing specified functions, meet the requirements of normative, technical and design documentation; 
- condition - a property of a vibration platform, in which the value of at least one parameter characterizing the property of performing a given function does not meet the requirements of regulatory, technical and design documentation;

- boundary condition - a property of a vibration platform [5], in which its further use for its intended purpose is unacceptable and impractical, or the restoration of its serviceable or serviceable state is impossible or impractical (Table 7.1).

Table 7.1 Criteria for the limiting state of the components of the vibration platform

\section{Unit or unit name Limit state criteria}

Frame structures 1 . Tiring transverse cracks along the perimeter of more than $40 \%$.

2. Concavity, twisting and other damage exceeding permissible limits, for elimination of which it is necessary to completely dismantle the frame structure

Gear transmission 1. Limiting wear of teeth.

2. Crumbling of the working surface of the tooth with a total area of more than $25 \%$

Clutch coupling

Worn splines or bearing seat on the shaft or breakage of the shaft, in which it is necessary to replace it

Propeller shaft 1. Crack in pipes, forks along welded seams.

2. Limiting wear of spline joints.

3. Limit wear of the bores for the bearing shells

Failures are divided by reason of occurrence, nature of manifestation, interrelation, groups of complexity and method of detection. In addition, there are resource and degradation failures. The classification of failures depending on the nature of their occurrence and the course of development processes leading to the onset of failure are shown in Fig. 7.2.

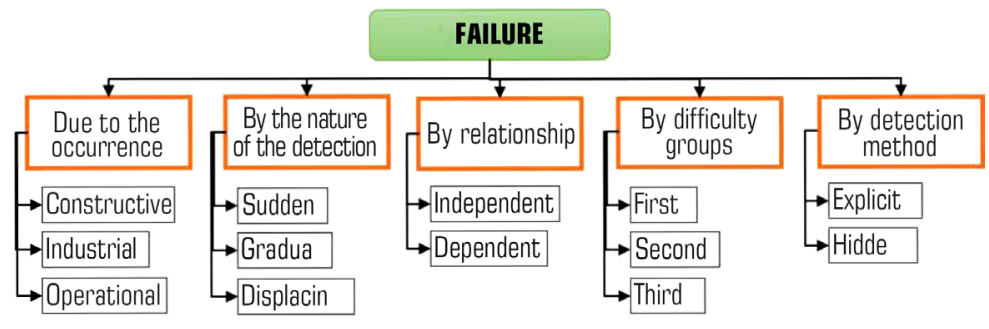

O Fig. 1.2 Classification of failures

Thus, improving the quality and reliability of a vibration platform [5] depends on many reasons, the main of which is the quality of vibration equipment. An integral part of quality is the accuracy class of the vibration platform or the error with which the vibrations are simulated. Therefore, 
the task of the study is not only to assess the reliability of existing structures, but also in new technical systems of complex structure. To solve such a problem, a set of criteria is proposed, the assessment of which will improve the quality of such technical systems.

\subsection{ENSURING THE RELIABILITY OF VIBRATION PLATFORMS IN THE CONSTRUCTION INDUSTRY, TAKING INTO ACCOUNT THE METHODS OF ANALYSIS}

Vibration platforms are widely used in the construction industry in the manufacture of concrete and reinforced concrete products. The effectiveness of their work largely depends on a fairly specific accounting of the operating forces of the system and the reliability of the parts of the vibration platforms. Currently, there are practically no works on the development of methods for assessing the reliability of vibration platforms in various modes of their operation. However, the practice of operating vibration platforms in the construction industry testifies to the frequent failure of parts and assemblies of these machines, which significantly reduces their performance in the operating modes provided for by the technology. As a result of this situation, formed goods may be defective. Therefore, the problem of reliability methods, determination of its criteria and improvement of the design of elements of vibration areas is urgent.

In accordance with DSTU 2861-94, reliability analysis for vibration platforms can be carried out in order to:

- checking the feasibility of the established requirements and assessing the likelihood of achieving the required level of reliability of the components and the object as a whole;

- verification of the effectiveness of the proposed (implemented) measures for finalizing the design, manufacturing technology, maintenance and repair strategies to improve reliability;

- predicting reliability and choosing the best ways to ensure or improve reliability.

Considering the above, the methods of analyzing the reliability of vibration platforms [1-6] are used to predict the reliability, maintainability, readiness and measures to guarantee safety, as well as to fulfill the consequences of forecasting with the given requirements.

Consequently, the tasks of reliability analysis and their scope depend on the stage of the life cycle of vibration platforms, the depth of development and reliability, the consequences of failures and their limiting states, and other factors.

The DSTU 2861-94 standard establishes two main approaches to the analysis of the reliability of all objects, including vibration platforms:

- analysis of the reliability of vibration platforms based on the results of measures and methods of ensuring reliability at the stages of design, production and operation in accordance with the reliability assurance program;

- quantitative methods for analyzing the reliability of vibration platforms based on the analysis of operating conditions, causes and mechanisms of failures, reliability indicators of elements, maintenance and repair strategies. 
The analysis of the reliability of vibration platforms presupposes a reliability assurance program (Fig. 1.3), according to the results of the implementation of which the desired result can be achieved.

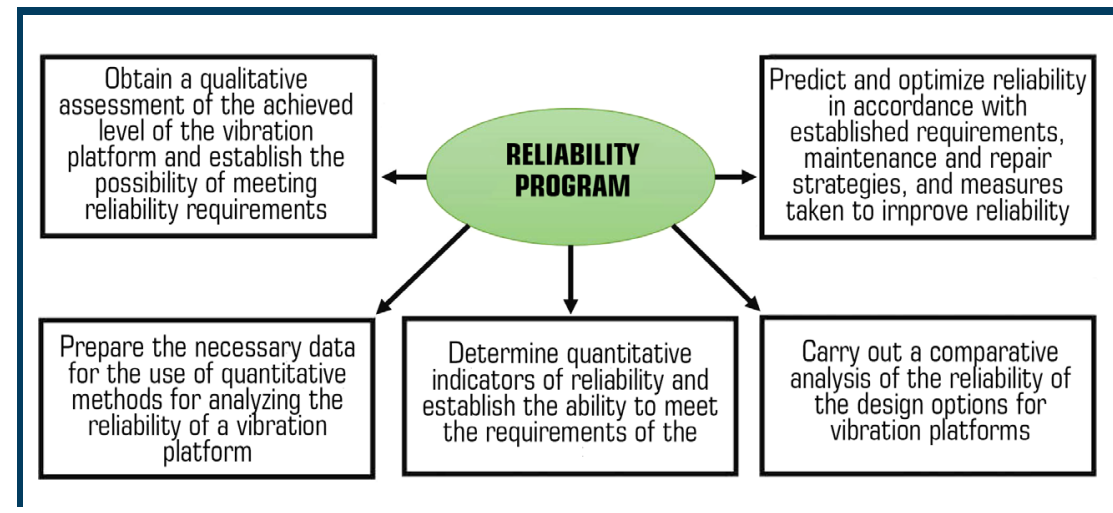

O Fig 7.3 Block diagram of the reliability assurance program

The analysis of the reliability of the vibration platform system is carried out using the following methods:

- qualitative analysis (determination of types of malfunctions, failure mechanisms of elements and their consequences for the system, analysis of the functional diagram of the system, analysis of the maintenance and repair system, construction of structural diagrams of system reliability);

- quantitative analysis (construction of mathematical models of the reliability of elements and systems according to the indicators under consideration, obtaining quantitative indicators of reliability by calculation or modeling, analysis of the importance of failures and sensitivity, assessment of the possibility of improving the characteristics of the system based on backup subsystems and maintenance and repair strategies).

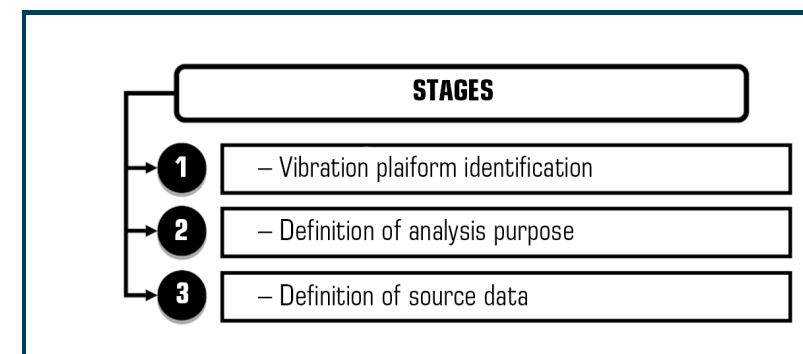

O Fig. 7.4 Diagram of the stages of the methodology for analyzing the reliability of vibration machines 
Accordingly, the assessment of the analysis results involves comparison with the mandatory reliability indicators and recommendations for measures to comply with the mandatory reliability indicators, which may include a design review, identification of weak points, imbalances, modes, replacement of parts with a high risk of malfunctions, development of alternative ways to improve reliability, implementation trade-off analysis and cost estimation of vibration platform design options as a whole.

\subsection{EXPERIMENTAL STUDIES OF RELIABILITY ASSESSMENT BASED ON FUZZY LOGIC}

The solution to the problem of increasing the reliability and efficiency of vibration machines is achieved by studying the parameters and characteristics of failures of the elements of a vibration machine in the operation stage to develop recommendations for determining the reliability indicators of units and parts of vibration machines with an increase in their efficiency.

To a large extent, the study of reliability indicators requires the involvement of a large number of observations, which in fact takes quite a significant amount of time. Taking this into account, it is necessary to carry out studies of reliability indicators using modern information technologies and alternative solutions to the problem.

When performing work on modeling the assessment of the reliability of vibration machines based on a fuzzy model, it is necessary to represent them in the form of fuzzy networks, the elements and sets of elements of which implement various components of fuzzy models and stages of fuzzy inference.

In his work, Lotfi Asker Zadeh presented a fuzzy productive model as follows [4, 7]:

$$
\text { (i): } Q ; P ; A \Rightarrow B: S ; F ; N
$$

where $Q$ - field of application of fuzzy products; $P$ - condition for the activation of the fuzzy production core; $A$ - condition of the kernel (antecedent); $B$ - kernel output (consequent); $S$ - method for determining the quantitative value of the degree of truth of the kernel output; $F$-coefficient of confidence of fuzzy products; $\mathrm{N}$ - post condition of the productive rules.

A fuzzy imitation of the relationship between antecedent and consequent can be viewed as fuzzy production:

if $x \in A$, then $y \in B$;

$X$ - domain of definition of the antecedent;

$A$ - fuzzy set visible on $X$;

$\mu_{A}(E) \in[0,1]$-membership function of an odd $\operatorname{set} A$;

$Y$ - area of definition of the consequent;

$B$ - fuzzy set defined on $Y$;

$\mu_{B}(E) \in[0,1]-$ membership function of an odd set $B$. 
If the ratio function of odd sets $A-\mu_{A}(E)$, is known, then for odd sets $B$, the ratio function is determined by the composition rule:

$$
\mu_{B}(C)=\sup _{x \in X}\left\{T\left(\mu_{A}(x), \mu_{R}(x, y)\right)\right\}
$$

where sup - operation of determining the upper limit of the sets of parts; $T$ - T-norm operation.

When modeling the failures of vibration machines as a rule for calculating fuzzy implication, the classical fuzzy implication of L. Zadeh:

$$
\mu_{R}(x, C)=\max \left\{\min \left[\mu_{A}(x), \mu_{B}(y)\right],\left[1-\mu_{A}(x)\right]\right\} .
$$

For the purpose of inference, the main methods in a fuzzy production model are forward and backward inference. Direct inference is based on such a concept as fuzzy modus ponens.

In the process of developing a fuzzy production model, the assessment of failures of vibration machines requires the formulation of certain conditions $X=\left\{E_{i}\right\}, i=\overline{1, n}$ - factors that are the source of failures, and therefore the entire range of conclusions $Y=\left\{y_{v}\right\}, j=\overline{1, m}$ is an indicator of failures of various elements and components of vibration machines.

Based on the previously established objects and concepts of the systems under consideration, namely vibration platforms, it is necessary to formulate the corresponding linguistic variables:

$M$ - electric motor;

$S$ - synchronizer;

$C$ - clutch;

$R$ - bearing (roller);

$P$ - propeller shaft;

$S P$ - support;

$F$ - frame (vibration plate).

Let's take B as the initial linguistic variable - the level of failure.

Let's define terms for input and output linguistic variables. For input linguistic variables $P, R, M$ let's introduce term-sets \{critically low, low, average, high, critically high\}, for $S, C, S P, F-\{$ low, medium, high $\}$. The term sets of the initial linguistic variable describe the failure detection rate - absent, unlikely, low, high enough, critically high\}.

The level of failure of a vibration platform is estimated in the process of fuzzy inference, using a large number of fuzzy rules that make up the aggregate knowledge base of a given subject area, represented in the form:

If $\left(x_{1}\right.$ is $\left.A\right)$ and $\left(x_{2}\right.$ is $\left.B\right)$, then $(y$ is $C)$,

where $A, B, C$ - linguistic values, identified in a fuzzy way through the corresponding membership functions for the variables $x_{1}, x_{2}$ and $y$. 
As a result of the study, a fuzzy knowledge base was determined, presented in the form of certain rules [7].

For further modeling of this kind of system, the Fuzzy Logic Designer software toolkit is used, which is a MATLAB b2020 extension package containing tools for designing a fuzzy logic system [6].

When determining the shapes of the curves of membership functions, it is taken into account that they are constructed subjectively according to the results of a survey of experts, therefore, in a sense, they are "approximate». The most common membership function is of the Gaussian type $[8,9]$, but in practice, the shape of the membership function curves is chosen based on the complexity of the calculations. The most widespread are triangular and trapezoidal membership functions due to their versatility and lower requirements for computing resources in their hardware implementation.

To display the selected fuzzy subsets of linguistic variables, let's them. The parameters of the input membership functions are shown in Fig. 7.5.

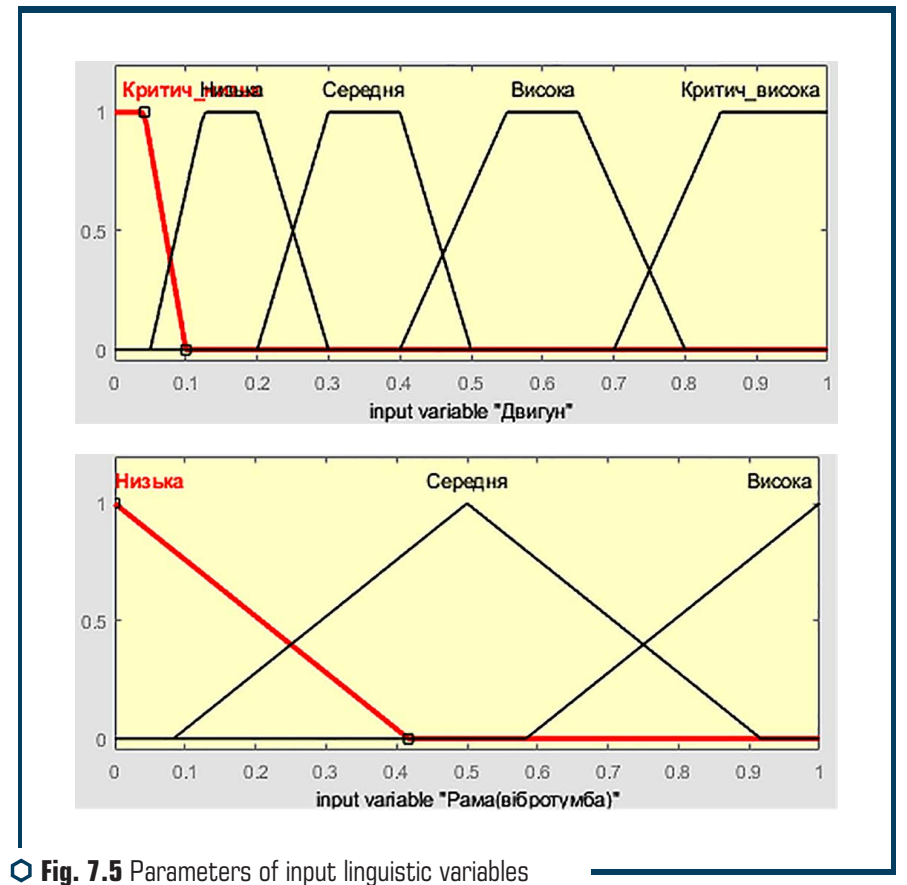

The Mamdani algorithm, which has received the greatest practical application in fuzzy modeling problems and consists in the application of a mini-maximum composition of fuzzy sets, is used as a mechanism for the fuzzy logical inference being developed. 
The process of processing fuzzy inference rules in this case consists of four stages:

1. Fuzzification, which consists in determining the degree of truth, that is, the value of the membership function for the premises (left-hand sides) of each rule.

2. Fuzzy inference, which consists in applying to the conclusions (right side) of the rules of the calculated truth value for the premises of each rule. As the inference rules in the Mamdani method, the minimum (min) operation is used, which "cuts off» the membership function of the rule conclusion by height, which corresponds to the calculated degree of truth of the rule prerequisite.

3. A composition that combines, using the maximum (max) operation, all fuzzy subsets defined for each variable output, and forms one fuzzy subset for each variable output.

4. Defasification, which realizes the scalarization of the composition result, i.e. transition from fuzzy subset to scalar value.

The scheme of the described fuzzy inference system implemented in the MATLAB medium is shown in Fig. 7.6.

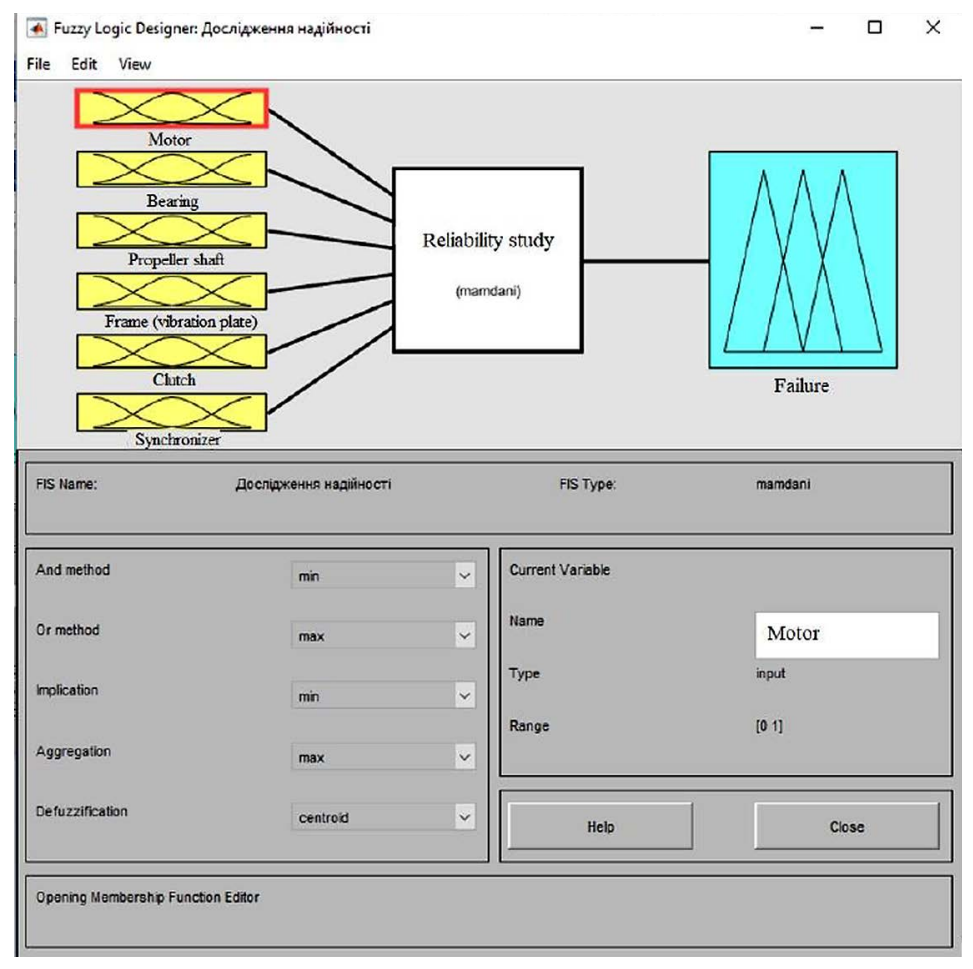

O Fig. 7.6 Scheme of a fuzzy inference system in MATLAB 
This system makes it possible to assess the failures of vibration platforms based on the input linguistic variable, the parameters of which are shown in Fig. 7.7.

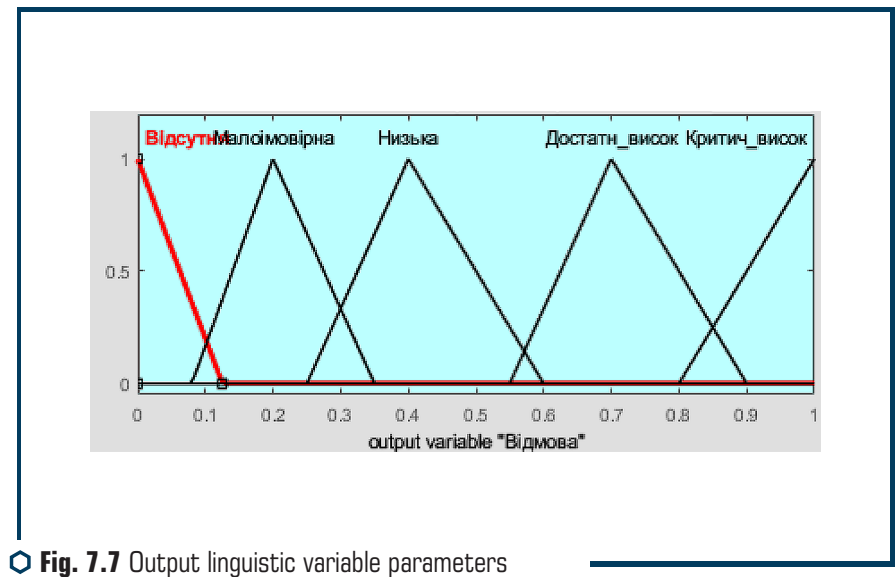

When performing the appropriate calculation, it is possible to preliminarily assume based on certain studies and observations that have input data, namely:

1. Engine - probability of failure 0.2 .

2. Bearings - probability of failure 0.7 .

3. Propeller shafts - probability of failure 0.7 .

4. Frame (vibration plate) - probability of failure is 0.1 .

5. Clutch - probability of failure is 0.4 .

6. Synchronizer - probability of failure 0.25 .

Thus, taking into account the corresponding coefficients, let's obtain the results of constructing fuzzy logic, which in this case will be based on certain 27 rules, according to which the overall failure rate of the vibration platform will be 0.624 (Fig. 7.8).

Accordingly, based on this range of values, it can be argued that the level of failure of the vibration platform is at a sufficiently high level.

Conducted similar studies of the presented fuzzy model for different sets of initial data also showed acceptable results (Fig. 7.9-7.12).

Failure to operate the vibration platform leads to downtime of the entire technological line and damage to the concrete mixture that has already been supplied to the line. In turn, this approach as a whole gives a clearer idea of which constituent elements need to be paid more attention to during the repair and maintenance of vibration platforms.

The use of this approach can significantly reduce the cost of maintaining vibration platforms and, accordingly, reduce the downtime rate of the production lines of the shop. 


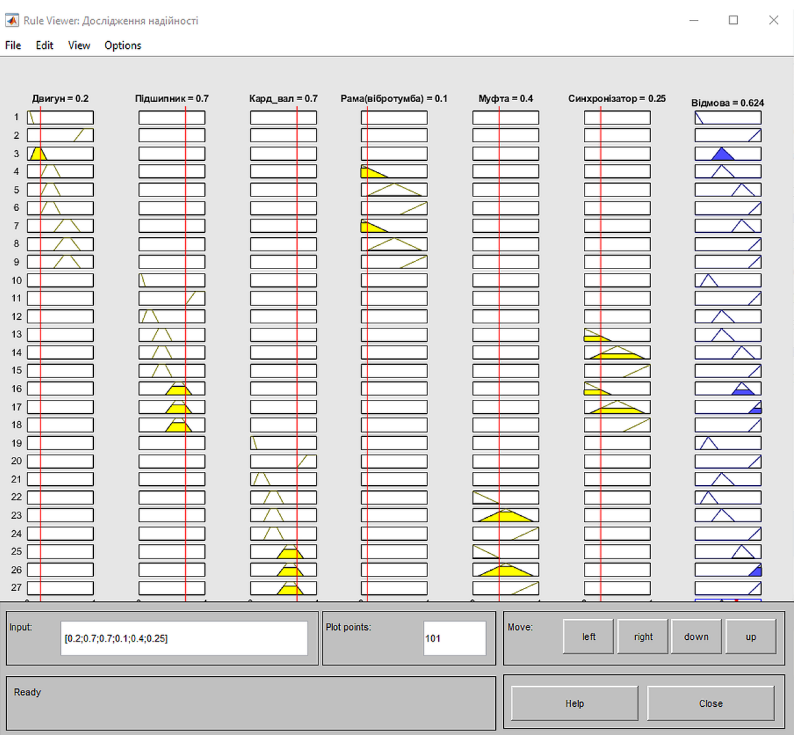

Fig. 7.8 Results of calculating fuzzy logic for 27 rules

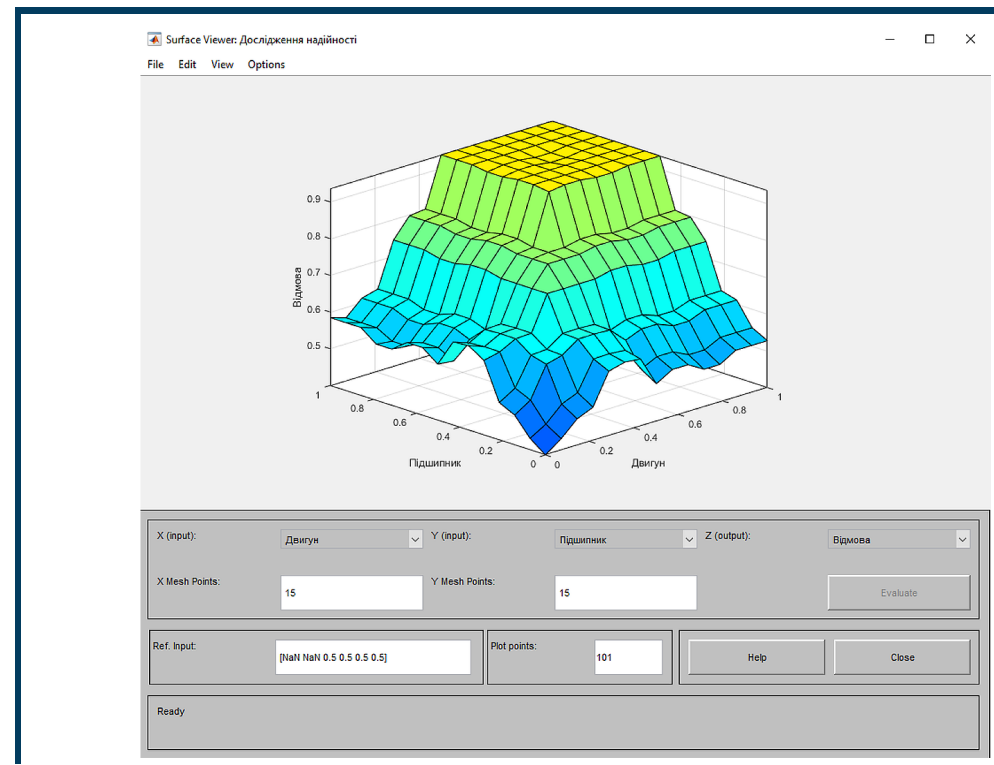

Fig. 7.9 Indicators of the effect of motor and bearings on failure 
A Surface Viewer: Досліаження надійності

File Edit View Options
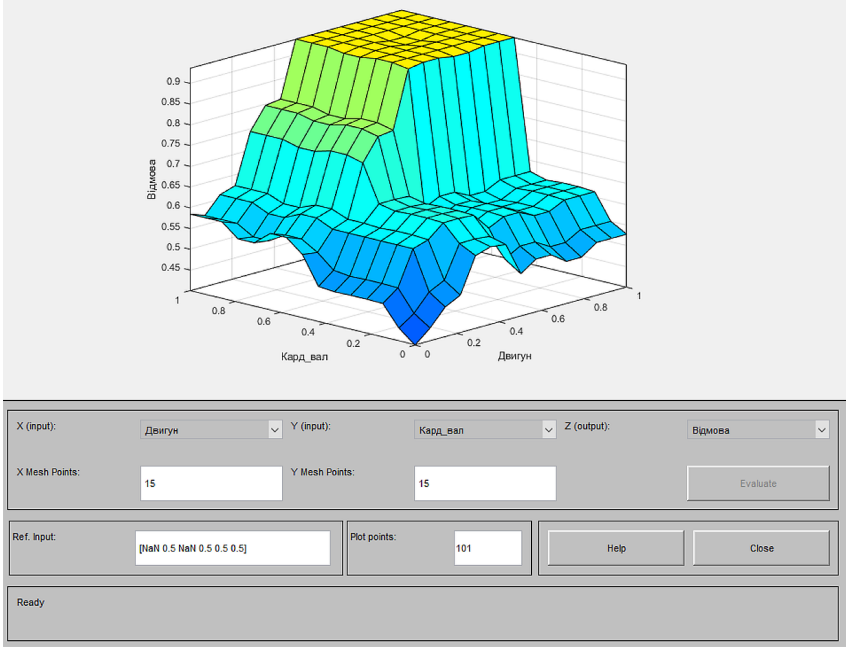

Fig. 7.10 Indicators of the effect of engine and propeller shafts on failure

(4) Surface Viewer: Аослірження надійності

$-\square \times$

File Edit View Options

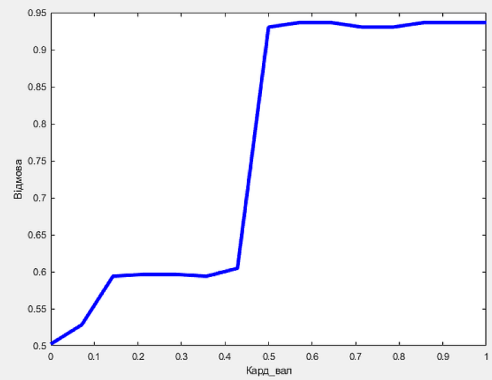

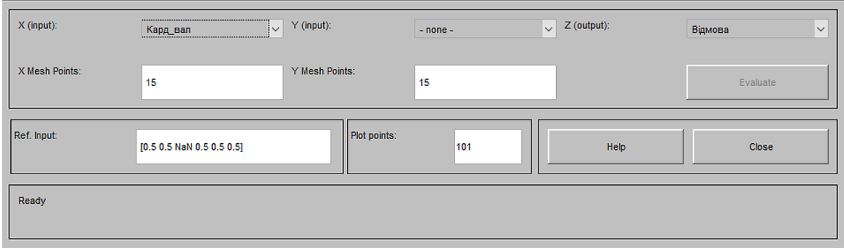

Fig. 7.11 Indicators of the effect of propeller shafts on failure 
4. Surface Viewer: Дослідження надйності

File Edit View Options
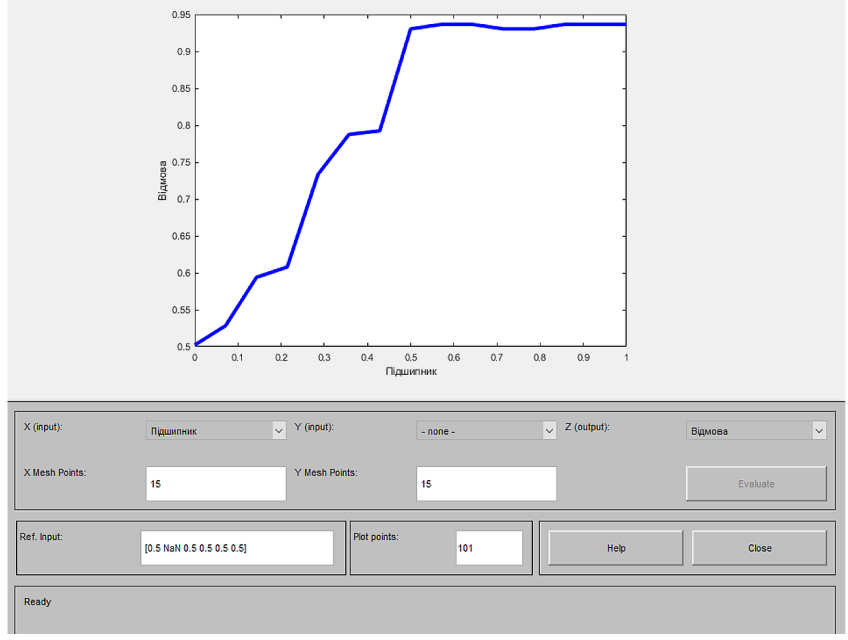

Fig. 7.12 Impact of bearing failure

\subsection{CALCULATION OF VIBRATION RELIABILITY OF A TECHNICAL SYSTEM}

When calculating the vibration reliability of optimal vibration protection, a vibration platform [7] was considered as a system described by the equation of motion:

$$
\ddot{u}+2 \varepsilon \cdot \dot{u}+\omega_{0}^{2} \cdot u=-a_{0}(t)
$$

Accordingly, the quality conditions are reflected in the form:

$$
|u(t)| \leq u_{*},|a(t)| \leq a_{*}
$$

where $a=a_{0}+\ddot{u}-$ absolute vibration acceleration. As a criterion for the optimality of the system in terms of reliability, the condition is selected so that the reliability functions (7.4) at the time instant $t=T_{*}$ acquire a maximum value.

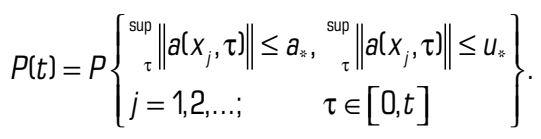


Taking into account the high reliability of systems for stationary oscillations, this condition, according to:

$$
P(t) \approx 1-\int_{0}^{t} \lambda(\tau) d \tau
$$

is equivalent to the condition $\lambda(\Gamma)=\min , \varepsilon, \omega_{0}$, where the average number of emissions per unit time is calculated for a rectangular region of available states (7.5).

It is proposed that the process $a_{0}(t)$ at the output of the system is narrow-linear with a carrier frequency $\theta$. In Fig. $\mathbf{7 . 5}$ the results of the corresponding calculation data $\lambda(\Gamma)$ are carried out at $u_{*}=10^{-3} \mathrm{~m}, a_{*}=20 \mathrm{~m} / \mathrm{s}^{2}$.

In Fig. 7.13 a graph is built according to the calculation $\lambda(\Gamma)$ performed for the case of an exponentially correlated process at the input with a correlation $K_{a_{0}}(\tau)=\sigma_{0}^{2} \cdot \exp (-a|\tau|)$. Considering the above, calculations have been made for the parameter values $m \varepsilon / \omega_{0}=0.5, a_{*}=2 \sigma_{0}$, $U_{*}=\left(\sigma_{0} / a^{2}\right) \cdot 10^{-4}$. Curves 1 in Fig. 7.5, 7.6 correspond to band emissions $|a|<a_{*}$, curve $2-$ band emissions $|U|<U_{*}$, curves 3 are plotted for the total number of emissions.

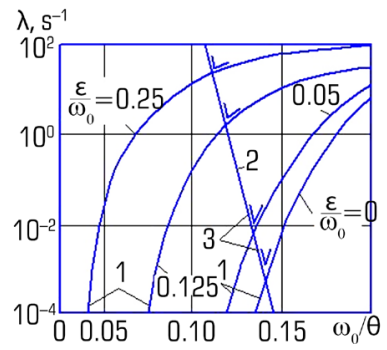

Fig. 7.13 Optimization in terms of reliability with a narrow-linear initial impact

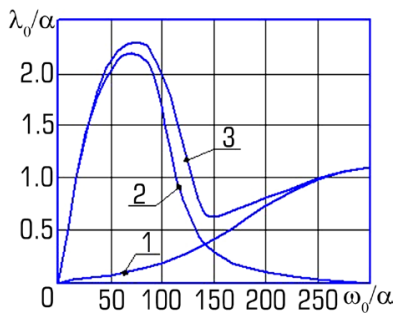

O Fig. 7.14 Optimization for reliability with an exponentially correlated initial action 
Basically, vibration loading is accompanied by a process of accumulating fatigue damage. The calculation of damages characterized by a one-dimensional process $v(t)$ was carried out accordingly. Accordingly, this process is rather slow, therefore, it requires a transition from $v_{k+1}=v_{k}+f\left(v_{k}, s_{k}\right)$ to a continuous analogue - a kinematic level:

$$
\frac{d v}{d t}=g(v, s)
$$

In such a case, the measure of damage $v(t)$ is an unfortunate function, $0 \leq v \leq 1$. In the above equation (7.5) $s(t)$ - some characteristic value for the load process $f(t)$, for example, amplitude. Taking this into account, the quality condition was chosen in the form $v<v_{*}=1, s<s_{*}(v)$, where $S_{*}(v)$ - the limiting value of the bearing capacity, taking into account the accumulation of damage. In this case, the reliability function:

$$
P(t)=P\left\{v(\tau)<1, s(\tau)<s_{*}(v), \tau \in[0, t]\right\}
$$

As a rule, as the damage caused by the fatigue process takes place:

$$
V_{k}=\sum_{j=1}^{k} \frac{1}{N\left(S_{j}\right)},
$$

where $N\left(S_{j}\right)$ - the number of cycles leading to failure with a characteristic $S_{j}$, then the condition of fatigued failure takes the form:

$$
\sum_{j} \frac{1}{N\left(S_{j}\right)}=1 .
$$

To assess the durability, a value $T_{*}$ equal to the duration of the load, which is necessary to achieve the condition $v=v_{*}=1$, is used. Therefore, with a low dispersion of durability, the value $T_{*}$ is close to the mathematical expectation $\langle T\rangle$. The value $T_{*}$ is called the expected durability. Accordingly, if do not take into account the probability of instantaneous destruction due to the process bursting beyond the level $s_{*}(v)$, then the expression for the expected durability takes the form:

$$
T_{*}=T_{e} \cdot\left[\int_{0}^{\infty} \frac{p(s) d s}{N(s)}\right]^{-1},
$$

where $T_{e}$ - some effective cycle period; $p(s)$ - distribution of the parameter $s$ - the loading process $f(t)$.

Having considered the suitable processes, it can be argued that for stationary normal narrowlinear load processes, the maximum value $m s(t)=f_{\max }(t)$ is taken as the characteristic value $m s(t)$. In this case, the distribution of the maximums of the normal process was found by the formula: 


$$
\begin{aligned}
& p_{\max }\left(v_{*}\right)=\frac{1}{\sqrt{2 \pi} \beta \cdot \sigma_{v}} \cdot\left\{\sqrt{\beta^{2}-1} \cdot \exp \left[-\frac{\beta^{2} \cdot\left(v_{*}-a\right)^{2}}{2\left(\beta^{2}-1\right) \cdot \sigma_{v}^{2}}\right]+\right. \\
& +\sqrt{2 \pi} \frac{v_{w}-a}{\sigma_{v}} \cdot \exp \left[-\frac{\left(v_{w}-a\right)^{2}}{2 \sigma_{v}^{2}}\right] \cdot \Phi\left(\frac{v_{*}-a}{\sqrt{\beta^{2}-1 \sigma_{v}}}\right),
\end{aligned}
$$

where

$$
\beta-\frac{\sigma_{\ddot{v}} \cdot \sigma_{v}}{\sigma_{\dot{v}}^{2}}=\frac{\lambda_{\max }(-\infty)}{\lambda(0)} .
$$

Calculations made according to the formula (7.7) with a power-law approximation of the fatigue curve:

$$
\begin{array}{ll}
N=N_{1} \cdot\left(\frac{s_{1}}{s}\right)^{m} & \left(s \geq s_{1}\right), \\
N \rightarrow \infty, & \left(s<s_{1}\right)
\end{array}
$$

give this expression:

$$
T_{*}=\frac{N_{1} \cdot X^{m} \cdot T_{e}}{2^{m / 2} \cdot \Gamma\left(1+\frac{m}{2}\right) \cdot P\left(X^{2}, m+2\right)},
$$

where $X=s_{1} / \sigma_{s} ; N_{1}, s_{1}, m$ - empirical constants; $P\left(X^{2}, T\right) m$ function $X^{2}$ - Pearson distribution. The same expression, expressed due to an incomplete gamma function $\Gamma(a, X)$, is:

$$
T_{*}=\frac{N_{1} \cdot X^{m} \cdot T_{e}}{2^{m / 2} \cdot \Gamma\left(1+\frac{m}{2}, \frac{X^{2}}{2}\right)} .
$$

Accordingly, for wide-linear load processes, there are different ways to select the load parameter, leading to different estimates of durability. To give an example of a cycle, the following maxima, maximum values, half-difference of subsequent maxima and minima, maximum process values at a certain characteristic time interval, etc. are considered. To schematize a given process by a load of some equivalent narrow-linear process, methods have been proposed: outliers (the number of cycles coincides with the average number of process zeros), maxima (the number of cycles is taken as the average number of process maxima), swing (a cycle is characterized by an amplitude equal to half the process increments between adjacent ones), full cycles (a method consisting in the sequential elimination of the process of intermediate cycles with increasing amplitudes), etc. 
Having considered the expression for the probability density $p(s)$ of the load parameter $s(t)$ in the case of a stationary normal process $f(t)$, the distribution of the maxima $p_{1}(s)$ is given by formula (7.8). By emission method:

$$
P_{0}(s)=\frac{s}{\sigma_{s}^{2}} \exp \left(-\frac{s^{2}}{2 \sigma_{s}^{2}}\right) ;
$$

by calculation method:

$$
P_{2}(s)=\frac{\beta^{2} \cdot s}{\sigma_{s}^{2}} \cdot \exp \left(-\frac{\beta^{2} \cdot s^{2}}{2 \sigma_{s}^{2}}\right)
$$

by full cycles method:

$$
P_{3}(s)= \begin{cases}\frac{\beta^{2} \cdot s^{\prime}}{\sigma_{s}^{2}} \cdot \exp \left(-\frac{\beta^{2} \cdot a^{2} \cdot s^{2}}{2 \sigma_{s}^{2}}\right) & \left(s<s_{k}\right) ; \\ \frac{c}{\beta} \cdot \frac{s}{\sigma_{s}^{2}} \cdot \exp \left(-\frac{s^{2}}{2 \sigma_{s}^{2}}\right) & \left(s<s_{k}\right),\end{cases}
$$

where $\beta$ - coefficient of wide linearity of the process; $a, c, s_{k}-$ some constants.

The nature of the dependence of the expected durability (7.7) on the nature of the wide linearity $\beta$ is shown in Fig. 7.7.

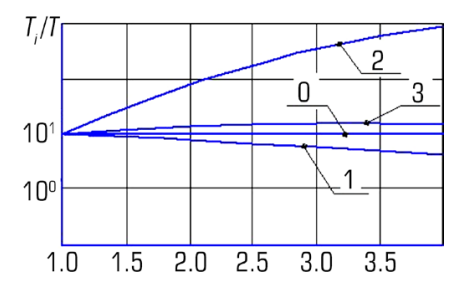

O Fig. 7.15 Comparison of estimates of expected durability when schematizing by different methods: 0 - bursting; 1 - maximums; 2 - swings; 3 - full cycles

The expected durability corresponding to the probability density $P_{i}(s)$ is indicated $T_{i}$ accordingly. The calculations took into account that $s_{1}=0, m=5$.

The maximum method gives a lower estimate for the expected durability, the swing and full cycles method overestimates this estimate. For narrow-linear processes, all of the above methods lead to practically the same results. 


\subsection{JUSTIFICATION AND APPLICATION OF THE PROVISIONS OF THE MATHEMATICAL THEORY OF RELIABILITY}

Let's consider the exploitation of a number of $N$ elements over time $t$. Let there be $N_{p}$ able-bodied and $n$ failed elements by the end of the service life. In this case, the relative number of failures $Q(t)$ :

$$
Q(t)=\frac{n}{N}
$$

If $N$ is large enough, it can be viewed $Q(t)$ as the probability of failure.

Then the probability of failure-free operation is $P(t)$ :

$$
P(t)=\frac{N_{p}}{N}=1-\frac{n}{N}=1-Q(t) \text {. }
$$

It follows from (7.10) that:

$$
P(t)+Q(t)=1
$$

The distribution of conditions in time is characterized by the distribution density function $f(t)$ of the operating time to failure:

$$
f(t)=\frac{d Q(t)}{d t}=\frac{1}{N} \frac{d n}{d t}=\frac{d P(t)}{d t} .
$$

In this case, the probability of failures and failure-free operation in the density function $f(t)$ is expressed by the dependencies:

$$
\begin{aligned}
& Q(t)=\int_{0}^{t} f(t) \mathrm{d} t . \\
& P(t)=1-Q(t)=1-\int_{0}^{t} f(t) \mathrm{d} t=\int_{t}^{\infty} f(t) \mathrm{d} t .
\end{aligned}
$$

Failure rate $\lambda(t)$ :

$$
\lambda(t)=\frac{f(t)}{P(t)}=\left\{f(t)=-\frac{d P(t)}{d t}\right\}=-\frac{d P(t)}{d t \cdot P(t)} .
$$

Let's rewrite (7.15) as:

$$
-\lambda(t) d t=\frac{d P(t)}{P(t)} .
$$


Integrating (7.16), let's obtain:

$$
\ln P(t)=-\int_{0}^{t} \lambda(t) d t \quad \text { or } \quad P(t)=e^{-\int_{0}^{t} \lambda(t) d t}
$$

During the period of normal operation, failures have a constant intensity, since worn out (gradual) failures do not appear yet, but only sudden failures occur, i.e.

$$
\lambda(t)=\lambda=\frac{1}{m_{t}}=\text { const, }
$$

where $m_{t}$ - mean time to failure, hours.

Probability of failure-free operation:

$$
P(t)=e^{-\int_{0}^{t} \lambda d t}=e^{-\lambda t}
$$

It obeys the exponential law of distribution of failure-free operation $t$ and is the same for any equal period of time (Fig. 7.16).

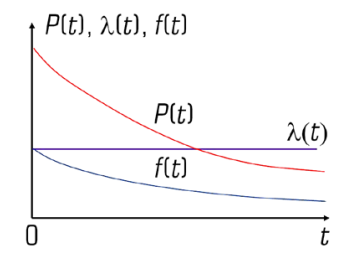

O Fig. 7.16 Function of probability $P(t)$ of failure-free operation, probability density $f(t)$ and failure rate $\lambda(t)$ according to exponential distribution during normal operation

The significant advantage of the exponential distribution is its simplicity: it has only one parameter.

Distribution density in general:

$$
f(t)=-\frac{d P(t)}{d t}=\lambda e^{-\lambda t}
$$

\subsection{RESEARCH OF INDICATORS OF RELIABILITY OF TECHNICAL SYSTEMS}

Experimental studies were carried out on the basis of the collected information on the development of vibration platforms to failure [1,3]. The received data of malfunctions was carried out 
by fixing by groups of prefabricated units, parts and elements, in order to separately determine the data on their operating time. Based on these data, an analysis of the operating time of the main elements between failures and the most frequent failures was carried out.

The studies carried out [2, 7, 10-19] identified the main prefabricated units and parts that fail: engine, gearbox, synchronizer, vibration exciter, propeller shafts, couplings, photographs of such failures are shown in Fig. 7.17.

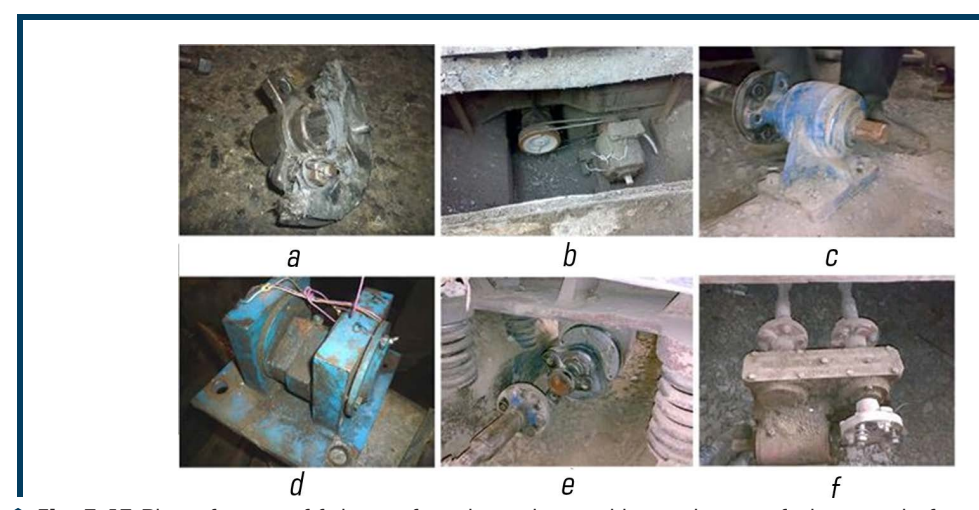

- Fig. 7.17 Photo fixation of failures of mechanical assemblies and parts of vibration platforms: $a$ - failure of the coupling; $b$ - failure of the electric motor; $c$ - failure of the bearing assembly; $d$ - failure of the vibration block; $e$ - failure of the propeller shaft; $f$ - failure of the synchronizer

According to the results of the study, it was found that most often propeller shafts and couplings failed. Destruction of bearings in vibration exciters was recorded only in a few cases.

In the investigated technical objects, depending on the design, the working body can consist of both separate elements such as a vibration plate or a form, and of a welded frame. In the course of research, in this group of elements, frequent defects were found as a result of contact of vibration plates with a form (Fig. 7.18).

Based on the results of the performed structural examinations, the main elements were established (Fig. 7.19), the failure of which has a direct impact on the reliability and safety of vibration machines.

The research methodology for the operating time of parts to failure consisted in conducting an experiment in real operating conditions of VB-10V vibration platforms.

Due to the frequent fixation of the identified failures of the propeller shafts of vibration platforms, the results of which are shown in Table 7.2. The construction of a statistical series for studying the distribution patterns of continuous random variables is possible with a sufficient number of observations. In this case (if $N>30$ ) the values obtained during observation in the variation series were grouped, and the entire series of values of the observed trait from $t_{1}$ to $t_{n}$ was divided into ordinary intervals. 


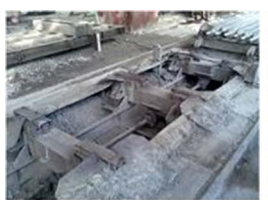

$a$

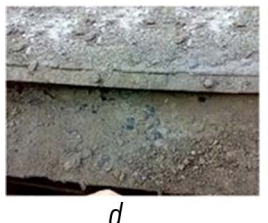

d

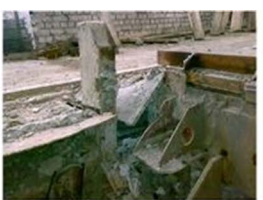

b

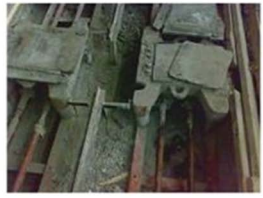

e

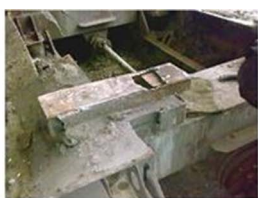

C

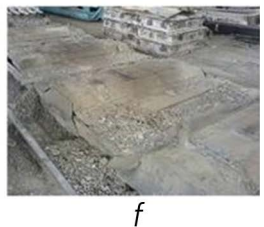

Fig. 7.18 Photo fixation of failures of the working bodies of vibration platforms: $a$ - failure of vibration plates; $b$ - deformation of the limiters; $c$-damage to the contact platform; $d$-damage to the protective casing; $e$ - damage to vibration plates; $f$ - blockage of the vibration platform

The number of intervals was determined from the condition of detecting the regularity of the distribution of the indicator values depending on the sample size $\mathrm{N}$.

The number of intervals was determined by the formula:

$$
K=\sqrt{N}
$$

where $N$ - the sample size.

For the convenience of further calculations, all intervals are assumed to be equal, targeted and without gaps. However, in some cases, when processing statistical data that are rather unevenly distributed, it is sometimes convenient in the area of the highest distribution density to choose narrower intervals than in the area of the smallest. The value of the interval was determined by the formula:

$$
h=\frac{T_{\max }-T_{\min }}{K-1},
$$

where $T_{\max }$ and $T_{\min }$ are the highest and lowest values of reliability indicators in the summary table of information.

The left and right boundaries of the distribution area are shifted by $0.5 \mathrm{~h}$ and taken accordingly:

$$
\begin{aligned}
& t_{0}=T_{\text {min }}-0.5 h, \\
& t_{k}=T_{\text {max }}+0.5 h,
\end{aligned}
$$

where $t_{0}$ - the left border of the first interval; $t_{k}$ - the right border of the last interval. 


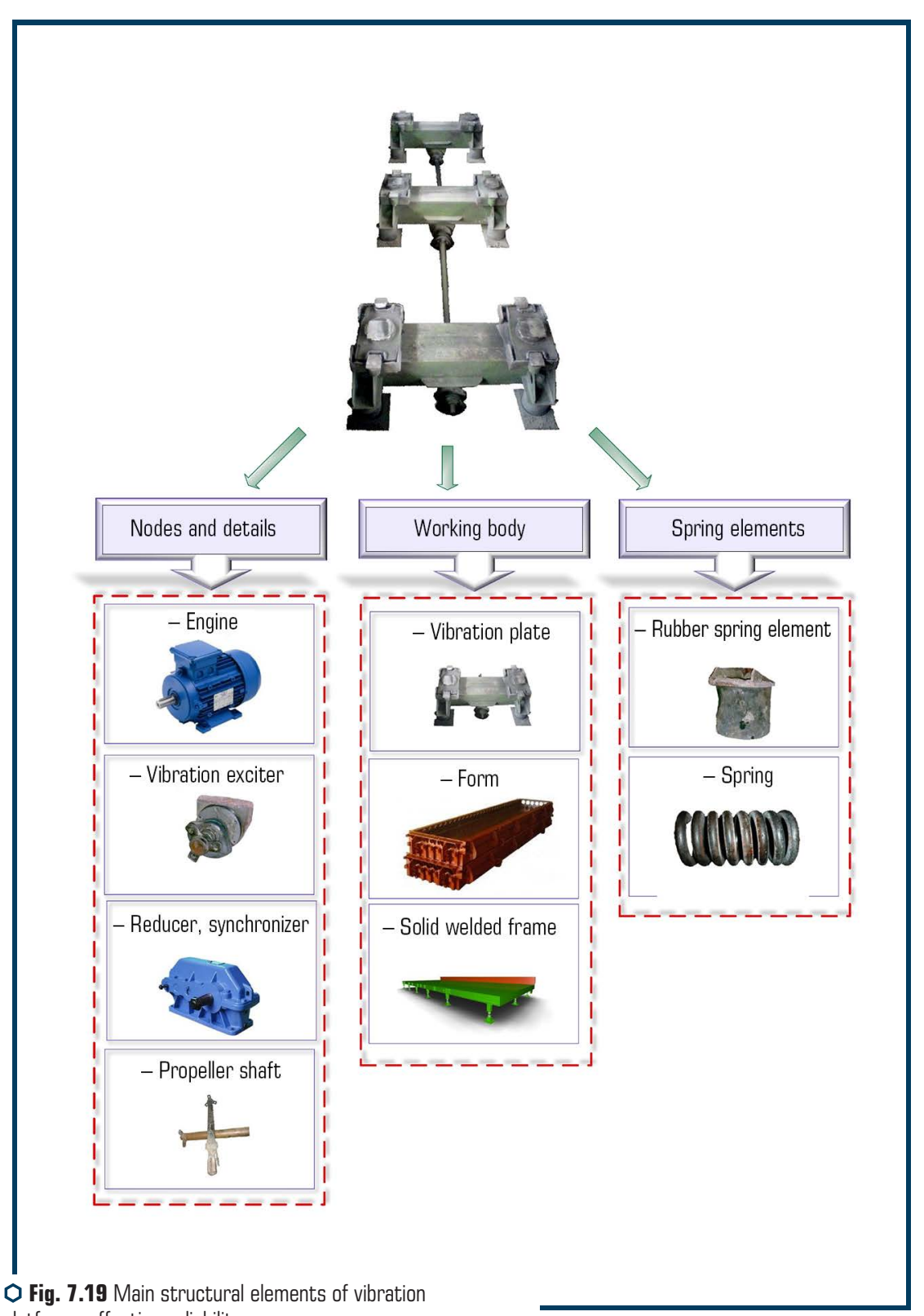
platforms affecting reliability 
Table 7.2 Operating time to failure of propeller shafts

\begin{tabular}{lllll}
\hline Operating time to failure, $\mathbf{h}$ & & \\
\hline 125 & 148 & 126 & 131 & 127 \\
130 & 155 & 135 & 164 & 133 \\
150 & 157 & 145 & 166 & 141 \\
162 & 178 & 175 & 192 & 163 \\
167 & 184 & 195 & 200 & 182 \\
186 & 188 & 202 & 242 & 239 \\
199 & 215 & 209 & 252 & 242 \\
222 & 226 & 268 & 261 & 271 \\
225 & 236 & 272 & 275 & 288 \\
287 & 269 & 280 & 288 & 290 \\
\hline
\end{tabular}

In subsequent calculations, the average value of the interval was taken:

$t_{a v i}=\frac{t_{i-1}+t_{i}}{2}$

where $t_{i}$ - value of the right limit of the $n$-interval.

After determining the boundaries of the intervals of the grouping, the frequencies $i$, the number of observations that fell into each of the intervals $\left[h_{i}\right], i=1, K$.

The sum of the frequencies of all intervals is equal to the sample size:

$\sum_{i=1}^{k} n_{i}=N=50$.

Another characteristic of the statistical distribution is the frequency $P_{t}$ (relative frequency), which is determined for each interval by the ratio of frequency $n_{i}$ to the total number of observations $N$ :

$\hat{P}=\frac{n_{i}}{N}$

Empirical distribution density of resources $\bar{f}_{i}(t)$ in the $i$-th interval $i=1,2,3 \ldots$

$\bar{f}_{i}(t)=\frac{n_{i}}{N \cdot h_{i}}$

Empirical function:

$$
\hat{F}_{2}(\mathrm{t})=\hat{P}_{1}+\hat{P}_{2} ; \hat{F}_{k}(\mathrm{t})=\sum_{i=1}^{k} \hat{P}_{i}
$$


The average value of the resource $T_{\text {r.av. }}$, hours was found by the formula:

$T_{\text {r.av. }}=\frac{\sum_{i=1}^{k} t_{a v} n_{i}}{N}$.

The standard deviation of the investigated quantity (resource) $\sigma$ :

$\sigma=\sqrt{\frac{\sum_{i=1}^{k} t_{\partial v}{ }^{2} n_{i}}{N}-T_{r . a v}^{2}}$.

The results of processing observational data using the sum method are summarized in Tables 7.3, 7.4.

Table 7.3 Numerical values of distribution parameters

\begin{tabular}{lllllll}
\hline $\begin{array}{l}\text { Interval } \\
\text { number }\end{array}$ & Interval limits & $\begin{array}{l}\text { Interval } \\
\text { mid point } \boldsymbol{t}_{a v}\end{array}$ & $\begin{array}{l}\text { Frequen- } \\
\mathbf{c y} \boldsymbol{n}_{\boldsymbol{i}}\end{array}$ & $\boldsymbol{T}_{a v}^{2}$ & $\boldsymbol{I}_{a v} \boldsymbol{n}_{\boldsymbol{i}}$ & $\boldsymbol{T}_{a v}^{2} \boldsymbol{n}_{\boldsymbol{i}}$ \\
\hline 1 & $111.25-138.75$ & 125 & 7 & 19251.6 & 971.25 & 134761.2 \\
2 & $138.75-166.25$ & 152.5 & 10 & 27639.1 & 1662.5 & 276391 \\
\hline 3 & $166.25-193.75$ & 180 & 8 & 37539.1 & 1550 & 300312.8 \\
\hline 4 & $193.75-221.25$ & 207.5 & 6 & 48951.6 & 1327.5 & 293709.6 \\
\hline 5 & $221.25-248.75$ & 235 & 7 & 61876.6 & 1741.25 & 433136.2 \\
6 & $248.75-276.25$ & 525 & 7 & 76314.1 & 1933.75 & 534198.7 \\
7 & $276.25-303.75$ & 580 & 5 & 92264.1 & 1518.75 & 461320.5 \\
& & & $\sum=50$ & & $\sum=10705$ & $\sum=2433830$ \\
\hline
\end{tabular}

Table 7.4 Calculation of characteristics by the method of sums

\begin{tabular}{lllll}
\hline Interval number & Interval mid point $\boldsymbol{t}_{\text {cauv }}$ & Frequency $_{\boldsymbol{n}_{\boldsymbol{i}}}$ & $\boldsymbol{K}_{\mathbf{1}}=\mathbf{1 1 0}$ & $\boldsymbol{K}_{\mathbf{2}}=\mathbf{8 4}$ \\
\hline 1 & 125 & 7 & 7 & --- \\
2 & 152.5 & 10 & --- & --- \\
3 & 180 & 8 & 33 & --- \\
4 & 207.5 & 6 & 25 & 61 \\
5 & 235 & 7 & 19 & 36 \\
6 & 525 & 7 & 12 & 17 \\
7 & 580 & 5 & 5 & 5 \\
& & & $\lambda_{1}=94$ & $\lambda_{2}=119$ \\
\hline
\end{tabular}


Auxiliary intervals are determined:

$$
\mu_{1}=k_{1}-\lambda_{1}
$$

The average value of the resource $T_{\text {r.av. }}$, hours, is found by the formula:

$$
T_{r . a v}=t_{a v . i}-\frac{h \mu_{i}}{N} .
$$

The mean square deviation of the resource $\sigma$, taking into account the auxiliary intervals:

$$
\sigma=h \sqrt{\frac{\mu_{2}-\mu_{1}^{2} / N}{N}} .
$$

Variation coefficient:

$$
V=\frac{\sigma}{T_{r . a v}}
$$

Actual value of the criterion $\lambda$ for extreme points:

$$
\lambda_{p}=\frac{1}{\sigma_{t}}\left(t_{j}-t_{j-1}\right), j=1, N,
$$

where $t_{j}$ and $t_{j-1}$ are adjacent information points. In this case, the condition $\lambda_{p}<\lambda_{T}$ is fulfilled.

Thus, as a result of checking the information for outliers, it was found that the minimum and maximum values of the sample are $t_{\min }=125$ and $t_{\max }=126$ with probability $\gamma=0.95$.

The histogram of relative frequencies (Fig. 7.20) indicates that in this case the process is subject to the Weibull distribution law:

$$
f(t)=\frac{b}{a}\left(\frac{t}{a}\right)^{b-1} \exp \left[-\left(\frac{t}{a}\right)^{b}\right]
$$

where $a$ and $b$ are distribution parameters $a \triangleright 0 ; b \triangleright 0$.

It was found that Pearson's criterion $\chi^{2}$ with a large number of observations reduces errors to a minimum, which compares favorably with other goodness-of-fit criteria:

$$
\chi^{2}=N \cdot h_{i} \cdot \sum_{i=1}^{k} \frac{\left[\hat{f}\left(t_{i}\right)-f\left(t_{i}\right)\right]^{2}}{f\left(t_{c p i}\right)}
$$

where $N$ - the total number of observations; $h_{i}$ - width of the $i$-th interval; $k$ - the number of staking intervals; $\hat{f}\left(t_{i}\right), f\left(t_{i}\right)$ - respectively empirical and theoretical probability density of distribution; $t_{a v i}$ - midpoint of the $i$-th interval for a continuous random variable or possible values for a discrete one. 


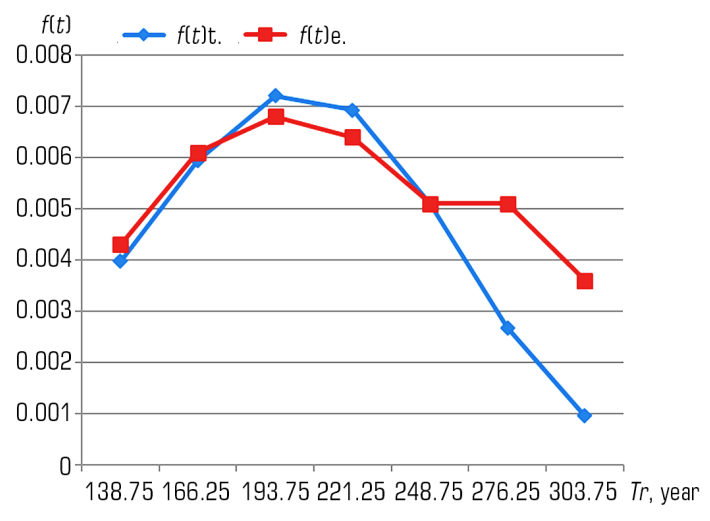

O Fig. 7.20 Concordance plot of empirical and theoretical distribution

Therefore, it was found that $P\left(r, x^{2}\right)=0.99$ exceeding the accepted significance level of 0.95 . This gives grounds to assert that the hypothesis that the empirical distribution belongs to cannot be rejected:

$$
P(t)=\exp \left[-\left(\frac{t}{a}\right)^{b}\right] .
$$

The Weibull distribution law is characterized by the dependences:

$$
F(t)=Q(t)=1-\exp \left[-\left(\frac{t}{a}\right)^{b}\right] .
$$

In relation to these calculations, the possibility of failure and trouble-free operation was obtained (Fig. 7.21).

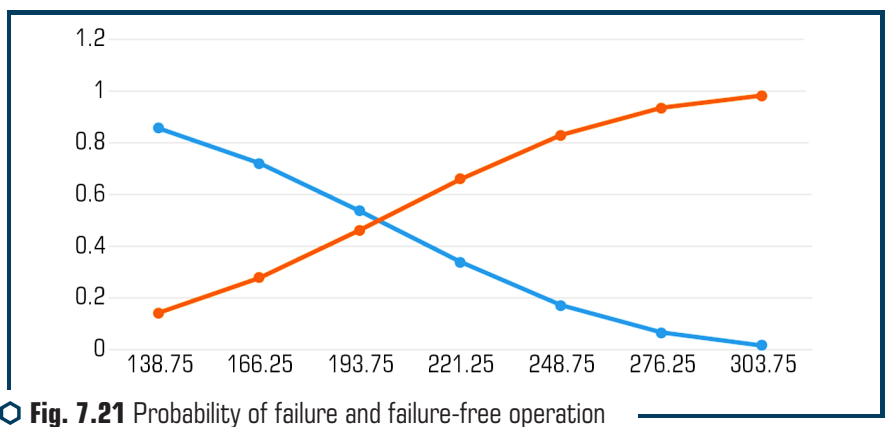




\subsection{DISCUSSION OF RESEARCH RESULTS}

The results of the studies carried out indicate a low level of reliability of the propeller shaft, which leads to long downtime during the unplanned repair time, which is 0.8-1.2 hours, if there are spare parts in stock. As a result of processing the statistical information of the propeller shaft reliability indicators, it was found that the average resource is 262 hours, the standard deviation is equal to $\sigma=53.2$ hours, the coefficient of variation is $V=0.27$.

A hypothesis is put forward about the error of the empirical distribution of resource indicators in comparison with the theoretical Weibull's law. The parameters of the Weibull distribution law were determined and graphs were constructed for the model of reliability and failures of propeller shafts, the graphs of the regularities of the distribution of resource indicators $P(t)$ and the distribution function $F(t)$ used in the developed recommendations.

Summarizing the presented calculation method, it is possible to build an algorithm for calculating the determination of the reliability indicators of vibration platforms (7.22).

\section{CONCLUSIONS TO SECTION 7}

1. The main states of reliability of a technical system and its elements have been investigated by the example of vibration platforms for compacting concrete mixtures.

2. The model for assessing the reliability has been developed based on fuzzy logic, implemented in the MATLAB b2020 medium.

3. The obtained results of modeling, taking into account the normalized indicators of reliability, show a "sufficiently high» level of failure.

4. When processing statistical data on the operating time to failure of the propeller shafts of vibration platforms, the Weibull distribution law has been established and the possibility of failure-free operation of such structural elements has been determined.

5. The obtained results of experimental data processing can be used in the development of new designs of similar technical systems.

\section{REFERENCES}

1. Nazarenko, I. I., Sviderskyi, A. T., Delembovskyi, M. M. (2013). Doslidzhennia nadiinosti kardannykh valiv vibromashyn budivelnoi industrii. Vibratsii v tekhnitsi ta tekhnolohiiakh. VNAU, 3 (71), 72-77.

2. Delembovskyi, M., Klymenko, M., Korniichuk, B. (2020). Doslidzhennia na osnovi nechitkoi lohiky modeli vyiavlennia vidmov vibroploshchadok. Zbirnyk naukovykh prats $\Lambda^{\prime} \mathrm{OHO \Sigma}, 111-112$. doi: https://doi.org/10.36074/25.12.2020.v1.38 
3. Delembovskyi, M., Klymenko, M. (2020). Metody pidvyshchennia nadiinosti ta efektyvnosti vibratsiinykh mashyn budivelnoi industrii. ICSR Conference Proceedings, 48-49. doi: http:// doi.org/10.36074/23.10.2020.v1.04

4. Delembovskyi, M., Klymenko, M. (2020). Zabezpechennia nadiinosti vibratsiinykh maidanchykiv budivelnoi industrii z urakhuvanniam metodiv analizu. Zbirnyk naukovykh prats $\Lambda^{\prime} \mathrm{OHO \Sigma}$, 26-28. doi: http://doi.org/10.36074/09.10.2020.v2.06

5. Delembovskyi, M., Terentiev, 0., Shabala, Ye. (2020). Echnology of implementation of the matlab environment in the investigation model of information security threatS. $\Lambda^{\prime} \mathrm{OHO} \Sigma$ mystetstvo naukovoi dumky. doi: http://doi.org/10.36074/2663-4139.15.08

6. Delembovskyi, M., Klymenko, M., Korniichuk, B. (2020). Rozrobka modeli otsinky nadiinosti vibroploshchadky na osnovi nechitkoi lohiky. Zbirnyk naukovykh prats $\Lambda^{\prime} \mathrm{OHO \Sigma}, 98-102$. doi: http://doi.org/10.36074/11.12.2020.v2.28

7. Nazarenko, I., Sviderskii, A. T., Delembovskii, M. M. (2015). Issledovanie nadezhnosti vibromashin stroitelnoi industrii. Mekhanizatsiia stroitelstva, 3, 44-49.

8. Seraya, 0. V., Demin, D. A. (2012). Linear Regression Analysis of a Small Sample of Fuzzy Input Data. Journal of Automation and Information Sciences, 44 (7), 34-48. doi: http:// doi.org/10.1615/jautomatinfscien.v44.i7.40

9. Domin, D. (2013). Artificial orthogonalization in searching of optimal control of technological processes under uncertainty conditions. Eastern-European Journal of Enterprise Technologies, 5 (9 (65)), 45-53. doi: http://doi.org/10.15587/1729-4061.2013.18452

10. Rogovskii, I. L., Delembovskyi, M. M., Voinash, S. A., Scherbakov, A. P., Teterina, I. A., Sokolova, V. A. (2021). Reliability indexes of vibrating platforms for compaction of construction mixtures. IOP Conference Series: Materials Science and Engineering, 1047 (1), 012026. doi: http://doi.org/10.1088/1757-899x/1047/1/012026

11. Nazarenko, I. I., Ruchynskyi, M. M., Sviderskyi, A. T., Kobylanska, I. M., Harasim, D., Kalizhanova, A., Kozbakova, A. (2019). Development of energy-efficient vibration machines for the buiding-and-contruction industry. Przeglad Elektrotechniczny, 95 (4), 53-59. doi: http:// doi.org/10.15199/48.2019.04.10

12. Nazarenko, I., Gavryukov, 0., Klyon, A., Ruchynsky, N. (2018). Determination of the optimal parameters of a tubular belt conveyor depending on such an economical. Eastern-European Journal of Enterprise Technologies, 3 (1 (93)), 34-42. doi: http://doi.org/10.15587/17294061.2018.131552

13. Nazarenko, I., Gaidaichuk, V., Dedov, O., Diachenko, 0. (2017). Investigation of vibration machine movement with a multimode oscillation spectrum. Eastern-European Journal of Enterprise Technologies, 6 (1 (90)), 28-36. doi: http://doi.org/10.15587/1729-4061.2017.118731

14. Nazarenko, I., Mishchuk, Y., Mishchuk, D., Ruchynskyi, M., Rogovskii, I., Mikhailova, L. et. al. (2021). Determiantion of energy characteristics of material destruction in the crushing chamber of the vibration crusher. Eastern-European Journal of Enterprise Technologies, 4 (7 (112)), 41-49. doi: http://doi.org/10.15587/1729-4061.2021.239292 
15. Luchko, J., Kovalchuk, V., Kravets, I., Gajda, O., Onyshchenko, A. (2020). Determining patterns in the stresseddeformed state of the railroad track subgrade reinforced with tubular drains. Eastern-European Journal of Enterprise Technologies, 5 (7 (107)), 6-13. doi: http:// doi.org/10.15587/1729-4061.2020.213525

16. Kovalchuk, V., Onyshchenko, A., Fedorenko, O., Habrel, M., Parneta, B., Voznyak, O. et. al. (2021). A comprehensive procedure for estimating the stressed-strained state of a reinforced concrete bridge under the action of variable environmental temperatures. EasternEuropean Journal of Enterprise Technologies, 2 (7 (110)), 23-30. doi: http://doi.org/ 10.15587/1729-4061.2021.228960

17. Nazarenko, I., Svidersky, A., Kostenyuk, A., Dedov, O., Kyzminec, N., Slipetskyi, V. (2020). Determination of the workflow of energy-saving vibration unit with polyphase spectrum of vibrations. Eastern-European Journal of Enterprise Technologies, 1 (7 (103)), 43-49. doi: http://doi.org/10.15587/1729-4061.0.184632

18. Bernyk, I., Luhovskyi, O., Nazarenko, I. (2018). Effect of rheological properties of materials on their treatment with ultrasonic cavitation. Materiali in Tehnologije, 52 (4), 465-468. doi: http://doi.org/10.17222/mit.2017.021

19. Luhovskaia, E. A., Yakhno, O. M., Bernyk, Y. N. (2012). Model of Technological Process of Ultrasonic Clearing of Elastic Surfaces Management. Naukovi pratsi Don NTU. Seriia: Hirnycho-elektromekhanichna, 23 (196), 154-166. 